https://www.journal-imab-bg.org

Case report

OPEN ACCESS

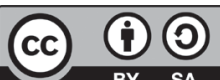

\title{
PHYSIOTHERAPEUTIC POTENTIAL BEFORE AND AFTER IMPLANTATION OF INTRATHECAL BACLOFEN INFUSION PUMP FOR TREATING SPASTICITY IN CHILD WITH CEREBRAL PALSY
}

\author{
Mariya Gramatikova, Stamenka Mitova \\ Department Kinesitherapy, Faculty of Public Health, Health Care and Sports, \\ South-West University, Blagoevgrad, Bulgaria.
}

\begin{abstract}
:
Purpose: To monitor and analyze physiotherapeutic potential before and after implantation of an intrathecal baclofen infusion pump for treating spasticity in a child with cerebral palsy.

Material: We present a 6-year-old girl with a massive spastic dystonic motor disorder, after hypoxic brain damage, based on an aspiration event in 2017. The first 6 months after the accident, the child is in a coma, 8 months in a state of awake coma. He has been conscious since the beginning of 2019. The diagnosis is bilateral spasticdyskinetic paralysis, structural epilepsy, suspected cerebral blindness, subluxation of the hip joints bilaterally. For the period from coma to now, the child has received the following treatment: gastrostomy, replacement with Button, application of ventriculo-peritenoic shunt, botulinum toxin therapy, implantation of intrathecal baclofen infusion pump for treating spasticity. From the third month after the accident until now, physiotherapy is performed 3-4 times a week, monitoring the condition and changes in the functional capabilities of the child.

Results: Before the baclofen pump, physiotherapy is mostly preventive against contractures and ankylosis. The child's functional capabilities and learning in motor activities are severely limited by central spasticity. 6 months after the placement of the baclofen pump, muscle tone decreased, and the child's physiotherapeutic potential increased.

Conclusions: The physiotherapeutic potential is significantly increased after implantation of an intrathecal baclofen infusion pump, as muscle tone is significantly reduced.
\end{abstract}

Keywords: pediatric neurorehabilitation, functional neurosurgery, baclofen pump, spasticity

\section{INTRODUCTION}

Cerebral palsy $(\mathrm{CP})$ is a neurodevelopmental disorder resulting from an injury to the developing brain. It is the most common form of childhood disability, with prevalence rates of between 1.5 and 3.8 per 1000 births reported worldwide [1]. Cerebral palsy is the most common physical disability of childhood, but the rate is fall- ing, and severity is lessening [2]. Cerebral palsy is a disorder of movement and posture arising from a non-progressive lesion in the developing brain. Spasticity, a disorder of increased muscle tone, is the most common motor difficulty and is associated with activity limitation to varying degrees in mobility and self-care [3].

One of the leading problems in children with cerebral palsy is the change in muscle tone and, as a result, various orthopedic and functional complications. Spasticity can be described as a disorder of the motor reflex, characterized by a speed-dependent increase in the tonic stretch reflex, with pathologically lively tendon reflexes resulting from hyperexcitability of the muscle stretching reflex [4].

A number of studies have followed the effect of various methods to affect the spastically increased muscle tone in children with cerebral palsy [5]. A number of authors believe that this is the leading problem for them [6].

Effective medical and surgical interventions include anti-convulsants, bisphosphonates, botulinum toxin, botulinum toxin plus occupational therapy, botulinum toxin plus casting, diazepam, dentistry, hip surveillance, intrathecal baclofen, scoliosis correction, selective dorsal rhizotomy, and umbilical cord blood cell therapy [2]. Oral baclofen, a gamma-aminobutyric acid (GABA) agonist, has been used in oral form to treat spasticity for some time, but it has a variable effect on spasticity, and the dose is limited by the unwanted effect of excessive sedation. Intrathecal baclofen produces higher local concentrations in cerebrospinal fluid at a fraction of the equivalent oral dose and avoids this excessive sedation [3].

Children and young adults with $(\mathrm{CP})$ have an increased risk of developing scoliosis, with a prevalence ranging from $11 \%$ to $29 \%$ [7]. Spinal deformity is a common issue in pediatric patients with an underlying neurological diagnosis or syndrome. Management of neuromuscular scoliosis (NMS) is a major part of the orthopedic care of such patients, as the deformity is often progressive, and may affect gait, seating and positioning. In addition, untreated large spinal deformities may be associated with pain and/or cardiopulmonary issues over time [8]. Surveillance programs for scoliosis in CP should be 
based on age and Gross Motor Function Classification System (GMFCS) level and should be initiated at a young age and continued into adulthood [9].

Joint contracture is a common problem among children with cerebral palsy [10]. Neurological research conducted reveals the presence of conditions including central quadriparesis (increased spastic tone - hand flexion and extension in the lower limbs), contractures and very live tendon reflexes. There is a muscle imbalance, gradually developing contractures and deformations and the creation of a pathological motor stereotype [11]. Spasticity control is a problem in the treatment of children with cerebral palsy, which prevents their functional recovery and mobility [12].

The causal relationship between muscle spasticity, muscle strength, gross motor skills and functional capabilities in children with cerebral palsy has been proven. There was a significant direct relationship between muscle spasticity and coarse motility as measured by GMFM, as well as a correlation between muscle strength and gross motility in these children. The relationship between gross motor skills and functional capabilities, and Daily Living Activities was also reported [5]. For the proper determination of the kinesitherapeutic potential, specialized tests should be used, which in turn provide a qualitative and rapid analysis of the condition of the patients [13].

An innovative method for the treatment of severe spastic syndromes is the surgical implantation of a baclofen pump. The method is applied to patients with severe spasticity, which significantly limits the patient's activity, complicates the care provided to him, does not allow the restoration of his functional capabilities, limits the possibilities of physiotherapy.

Purpose: To monitor and analyze physiotherapeutic potential before and after implantation of an intrathecal baclofen infusion pump for treating spasticity in a child with cerebral palsy.

\section{MATERIALS AND METHODS:}

We present a 6-year-old girl with a massive spastic dystonic motor disorder, after hypoxic brain damage, based on an aspiration event in 2017. The first 6 months after the accident, the child is in a coma, 8 months in a state of awake coma. He has been conscious since the beginning of 2019. The diagnosis is bilateral spastic-dyskinetic paralysis, structural epilepsy, suspected cerebral blindness, subluxation of the hip joints bilaterally. For the period from coma to now, the child has received the following treatment: gastrostomy, replacement with Button, application of ventriculo-peritenoic shunt, botulinum toxin therapy - 2018, implantation of intrathecal baclofen infusion pump -11.2019 , for treating spasticity. From the third month after the accident until now, intensive physiotherapy is performed 3-4 times a week, one hour a day, monitoring the condition and changes in the functional capabilities of the child. Occupational therapy and speech therapy are also used 3 times a week.

Kinesitherapy applies the following methods: manual-soft tissue mobilization, mobilization of periph- eral joints, stretching, positional treatment, proprioceptive training, training in postural control, training in global body movements by the Bobat method, Galileo therapy. Muscle-inhibitory techniques are also applied, which due to the co-contraction performed by the child have the effect of post-isometric relaxation, which restores not only the strength of the muscles, but also the active movement in them [11].

At home, parents are trained and apply positioning by changing and fixing the position of the child's body. The patient uses splints to maintain dorsiflexion in the ankle joint, adductor for hip joints, as well as a corset for neuromuscular scoliosis.

\section{RESULTS:}

Prior to the implantation of the baclofen pump, the test findings are:

Sensorimotor: MER: BSR, TSR, PSR, ASR - living, with partially dilated reflex zones on the lower extremities. Babinski reflex - bilaterally positive.

Muscle tone: Massive spastic dystonic motor disorder, but with asymmetry of tone, and for the right, there is a stronger stretching tone compared to the left side. The child voluntarily controls the left half of the body better. For the upper limbs, significant tone of the internal rotators. Hypotonic torso muscles.

Sensitivity: by touch, by two-way comparison, approximately preserved and symmetrical.

Coordination: Coordinating tasks cannot be performed. Volitional control - on the left upper and lower limb.

Tonus / Strength: Differentiated opinion about muscle strength is not possible due to impaired innervation and massive spastic dystonic motor impairment. Bilateral structural Pes equinus, more pronounced on the right, is observed. Abduction deficit of both hip joints, symmetrically, up to about $20^{\circ}$ in hip flexion. Valgus wrong axial position when standing up. The head is not controlled voluntarily.

Anglometry: shoulder joints are bilaterally mobile only up to $90^{\circ}$ flexion and $90^{\circ}$ abduction. Hand in a fist position, thumb in flexion, elbow in flexion. Lower limbs in extension and adduction.

Radiology findings: bilateral hip joints dysplasia. Reimers Migration Index: right 41\%; left 39\% in 2019. The same index in 2018 is: right - 39\%, left - 26\%, which shows an increase in the strength of hip joints luxation bilaterally due to hypertonic.

She does not control hår head voluntarily. It does not change the position of the body voluntarily.

In conclusion, it can be said that the physiotherapeutic potential before the implantation of the baclofen pump is very weak due to the strong spasticity of the whole body. The limited volume of movement in almost all joints also limits the training in global movements. Thus, physiotherapy aims at prevention against myoarticular contractures, and in practice, it is not possible to work for motor training, development of muscle strength and control, etc. 
Up to six months after implantation of the baclofen pump: no major change in spastic dystonic motor impairment was observed. The physiotherapeutic potential remains as before the baclofen pump.

From the sixth to the ninth month after the implantation of the baclofen pump: in this period, there is a tendency to significantly reduce spasticity and restore the passive volume of movement in all joints. The physiotherapeutic potential is significantly increased. Kinesitherapy procedures include motor training of global motor functions.

Positions for muscle inhibition and relaxation during the procedure: barbarian seat; lay in a semi-lateral position on the abdomen; 20 minutes sitting, on the heel. The head is held or placed forward (middle or side).

The tone is significantly lower than before the implantation of the Baclofen pump. Muscular dystonia of the lower limbs is minimal, more in the upper. Assessment of muscle strength on a scale from 0 to 5 of the Manual Muscle Testing for the lower and upper limbs is 2 for both sides.

Anglometry: shoulder joints on both sides are now movable up to $180^{\circ}$ flexion and $180^{\circ}$ abduction. The hands are relaxed in their physiological norms. The knee is relaxed in slight flexion. Plantar flexors $-0^{\circ}$ on both sides. The Silfverskiold test is positive for both parties. The Tardieu test is negative for both parties. No catch on both sides. Popliteal angle: $0^{\circ}$ on both sides, no grip. Hip joints - internal rotation $60^{\circ}$, external rotation $40^{\circ}$ on both sides.

Thomas test (m.iliopsoas): negative bilaterally. Duncan (m.rectus femoris) test negative bilaterally. Slow knee test on both sides $\left(45^{\circ}\right)$. No grip. When standing, the feet have toes on both sides and with the presence of valgus.

Deep tendon reflexes: show a lively reaction, symmetrical, in all limbs. Babinsky positive bilaterally. Negative clone.

The skeletal system shows scoliosis on the right, thoracolumbar hyperkyphosis.

After the baclofen pump, the child showed the first suction movements, she began to hold an object in her right hand on her own. There is a development of motor skills and improvement in interaction.

From the ninth to the twelfth month after implantation of the baclofen pump: the physiotherapeutic potential increases progressively. Head control is better but not constant. The child can now turn from bed to bed and vice versa independently. She can sit in the position of a supported outstretched seat, with the support in front of the body. She stands on his knees, his torso resting on a barbarian. The child began to stand on his elbows. Stands on the elbow in a lateral position with minimal support (holding) by the therapist.

From a bed with fixed folded lower limbs, the therapist grabs the child by the arms and lifts the body to a seat, during this period began active contractions in the abdominal area, as well as active folding of the upper and lower limbs to move from lying to a seat. Until now, the child was passive in this performance.

When training in climbing, the lower limbs are folded alternately with very slight irritation of the feet, but the upper limbs remain passive. The control of the head is sometimes good, but sometimes it stands still.

When verticalized, it no longer bends the knee joints. She stands straight with the elbow support of the cat as the therapist holds the pelvis in the ventral direction because there is not yet enough force to keep the hip joints in a neutral position. The feet are also fixed with the therapist's feet. We apply weight to the waist in order to load the joints and lower limbs.

Before the baclofen pump, physiotherapy is mostly preventive against contractures and ankylosis. The child's functional capabilities and learning in motor activities are severely limited by central spasticity. 6 months after the placement of the baclofen pump, spastic muscle tone decreased, and the child's physiotherapeutic potential increased.

\section{DISCUSSION:}

Prior to implantation of the baclofen pump, the physiotherapeutic potential of a child with bilateral spastic-dyskinetic paralysis is severely limited due to centrally caused muscle spasticity. Difficulties also arise from the fact that when taking baclofen as a medicine, the child is carried away, sleepy, and it is difficult to engage his attention.

Six months after pump placement, the physiotherapeutic potential progressively increases. Between the sixth and twelfth months of implantation of the baclofen pump, the child is trained to actively perform some of the global motor movements. It should also be borne in mind that our patient becomes blind after the accident, which further complicates motor training and recovery in general.

It is known that so far in Bulgaria, there are only three patients with implanted baclofen pumps, two adults (1 with multiple sclerosis and 1 after stroke) and one child for whom the case report is. Research continues in the future.

\section{CONCLUSIONS:}

The physiotherapeutic potential is significantly increased after implantation of an intrathecal baclofen infusion pump, as muscle tone is significantly reduced. 


\section{REFERENCES:}

1. Ryan JM, Cassidy EE, Noorduyn SG, O'Connell NE. Exercise interventions for cerebral palsy. Cochrane Database Syst Rev. 2017 Jun 11;6(6): CD011660. [PubMed]

2. Novak I, Morgan C, Fahey M, Finch-Edmondson M, Galea C, Hines A, et al. State of the Evidence Traffic Lights 2019: Systematic Review of Interventions for Preventing and Treating Children with Cerebral Palsy. Curr Neurol Neurosci Rep. 2020 Feb 21;20(2):3. [PubMed]

3. Hasnat MJ, Rice JE. Intrathecal baclofen for treating spasticity in children with cerebral palsy. Cochrane Database Syst Rev. 2015 Nov 13;(11): CD004552. [PubMed]

4. Avramova M. [Specialized kinesitherapy in children with child cerebral palsy.] [in Bulgarian] Sports and Science. 2019; 63(Extraordinary Issue):234-247. [Internet]

5. Avramova M. Effectiveness of
Specialized Kinesitherapy in Children with Spastic Hemiplegic Cerebral Palsy. J of IMAB. 2021 Jul-Sep; 27(3):3842-3846. [Crossref]

6. Avramova Ì. [The effect of Doman-Delacato and Perfetti methods in children with spastic hemiplgic cerebral palsy.] [in Bulgarian] Knowl Int J. 2018 Dec;28(2):449-454. [Crossref]

7. Pettersson K, Wagner P, RodbyBousquet E. Development of a risk score for scoliosis in children with cerebral palsy. Acta Orthop. 2020 Apr; 91(2):203-208. [PubMed]

8. Murphy RF, Mooney JF 3rd. Current concepts in neuromuscular scoliosis. Curr Rev Musculoskelet Med. 2019 Jun;12(2):220-227. [PubMed]

9. Hagglund G, Pettersson K, Czuba T, Persson-Bunke M, Rodby-Bousquet E. Incidence of scoliosis in cerebral palsy. Acta Orthop. 2018 Aug;89(4): 443-447. [PubMed]

10. Cloodt E, Wagner P, Lauge-
Pedersen H, Rodby-Bousquet E. Knee and foot contracture occur earliest in children with cerebral palsy: a longitudinal analysis of 2,693 children. Acta Orthop. 2021 Apr;92(2):222-227. [PubMed]

11. Gramatikova M. Application of muscle inhibiting techniques to children with cerebral palsy. $J$ of IMAB. 2020 Oct-Dec;26(4):3353-3355. [Crossref]

12. Parashkevova $\mathrm{P}$, Deleva $\mathrm{R}$, Mincheva P, Andreev A. A Study on Use of Neurodynamic Tests among Neurorehabilitation Professionals. $J$ of IMAB. 2019 Jan-Mar;25(1):24382442. [Crossref ]

13. Filipova M, Popova D, Bogomilova S, Nenova G. Kinesitherapeutic approach in patients with ischemic stroke treated with venous thrombolysis. J of IMAB. 2020 OctDec;26(4):3371-3373 [Crossref]

Please cite this article as: Gramatikova M, Mitova S. Physiotherapeutic potential before and after implantation of intrathecal baclofen infusion pump for treating spasticity in child with cerebral palsy. J of IMAB. 2022 Jan-Mar;28(1):42604263. DOI: https://doi.org/10.5272/jimab.2022281.4260

Received: 05/09/2021; Published online: 01/03/2022

Address for correspondence:

Assoc. Prof. Mariya Gramatikova, PhD

Department of Kinesitherapy, Faculty of Public Health, Healthcare and Sports, South-West University Neofit Rilski,

66, Ivan Mihaylov, 2700 Blagoevgrad, Bulgaria

E-mail: mari_gramatikova@abv.bg 